\title{
Cat on a hot tin roof (a nephrology zebra)
}

\author{
Samuel Wacrenier ${ }^{1} \cdot$ Jean Philippe Coindre ${ }^{1}$. Sophie Blanchi ${ }^{1} \cdot$ Giorgina Barbara Piccoli $^{1}$
}

Received: 29 March 2021 / Accepted: 12 April 2021 / Published online: 23 April 2021

(c) Italian Society of Nephrology 2021

Keywords Acute kidney injury $\cdot$ Cathinone drug $\cdot 3-M M C$

\section{Case description}

A 66-year-old man, the headmaster of a secondary school, was referred to the hospital for acute kidney injury (AKI).

When questioned, he stated that he did not abuse alcohol, smoke tobacco or use intravenous or other illegal drugs. His medical history included HIV infection known since 1986, currently with undetectable viremia and CD4+lymphocytes at $900 / \mathrm{mm}^{3}$. This HIV infection was complicated by a colic Kaposi's sarcoma in 1993, now in complete remission, and stage III chronic kidney disease (CKD), which was associated with Tenofovir toxicity. His medical history included previous acute hepatitis $\mathrm{B}$, prostate adenocarcinoma treated by radiotherapy followed by therapeutic ultrasound and currently in complete remission, basal cell carcinoma of the left forearm, hypertension and dyslipidemia.

His current treatment includes Irbesartan, Hydrochlorothiazide, Modamide, Atorvastatin, Phosphoneuros and Juluca (Rilpivirine Chlorhydrate and Dolutegravir Sodium).

The diagnosis of AKI, and the consequent referral, followed the results of a routine biological test, that showed a creatinine level of $284 \mu \mathrm{mol} / \mathrm{L}(3.2 \mathrm{mg} / \mathrm{dL})$, increased from his baseline level of $136 \mu \mathrm{mol} / \mathrm{L}(1.5 \mathrm{mg} / \mathrm{dL})$. The patient did not report any obvious precipitating element such as diarrhea or vomiting. The last therapy introduced was JULUCA, 6 months earlier.

Questioning revealed that the patient had been to a party and had had homosexual intercourse with a chlamydiainfected partner a few days earlier. He reported having been deeply psychologically affected by the lock-down period (implemented by the French government in the context of the SARS-COV-2 epidemic).

Samuel Wacrenier

sam.w@hotmail.fr

1 CH Le Mans: Centre Hospitalier du Mans, Le Mans, France
On physical examination, he was asymptomatic (temperature $37.3{ }^{\circ} \mathrm{C}$, blood pressure $136 / 84 \mathrm{~mm} \mathrm{Hg}$, pulse 65 beats per minute, respiratory rate 18 breaths per minute). There were no clinical signs of dehydration or hyperhydration. Greenish anal discharge was noted. There was no sign of other clinical infection and the remainder of the examination was normal.

Abdominal ultrasound revealed a right kidney of $11 \mathrm{~cm}$ and a left kidney of $11.7 \mathrm{~cm}$, without dilatation of the urinary tract, but with right calyceal lithiasis.

Hepatitis C serology, HIV RNA viral load, Chlamydia trachomatis, Neisseria gonorrhoeae, Trichomonas vaginalis and Mycoplasma genitalium polymer chain reactions (PCR) on blood sample were all negative, as was SARS-COV 2 PCR on nasopharyngeal swab. The remaining biology is reported in Table 1.

\section{Case solution}

This patient presented acute kidney injury of tubulo-interstitial profile with an increased creatinine phosphokinase (CPK) level, occurring in the setting of a festive evening a few days earlier, in a situation of psychological vulnerability. In this context, in the absence of infectious or autoimmune diseases, the first hypothesis is drug consumption, the recreational drug 3-methylmethcathinone, also known as 3-MMC, or "the 3" being the most likely candidate.

After re-discussion, the patient admitted he had taken 3-MMC for the first time the previous week.

3-MMC is a recreational drug that belongs to the synthetic cathinone family [1]. The amphetamines formerly produced in plants, namely cathinone (khat) from the plant Catha edulis, were replaced in the 1990s by synthetic derivatives including 4-MMC (mephedrone), 4-MEC (4ᄀmethylcathinone), MDPV (3,4ᄀmethylenedioxypyrovalerone), and alpha-PVP. These substances, which were initially 
Table 1 What is your diagnosis?

\begin{tabular}{|c|c|c|}
\hline Variable & Reference range & On admission \\
\hline \multicolumn{3}{|l|}{ Laboratory data } \\
\hline \multicolumn{3}{|l|}{ Blood } \\
\hline Hemoglobin (g/dL) & $13-17$ & 13.9 \\
\hline Hematocrit $(\%)$ & $38-49$ & 40 \\
\hline Platelet count (per $\mu \mathrm{L})$ & $150,000-400,000$ & 206,000 \\
\hline White-cell count (per $\mu \mathrm{L})$ & $4000-10,000$ & 7500 \\
\hline Sodium (mmol/L) & $136-145$ & 141 \\
\hline Potassium (mmol/L) & $3.4-4.5$ & 3.6 \\
\hline Chloride (mmol/L) & 98-107 & 104 \\
\hline Carbon dioxide $(\mathrm{mmol} / \mathrm{L})$ & $22-29$ & 26 \\
\hline Urea nitrogen $(\mathrm{mmol} / \mathrm{L})$ & $8-25$ & 56 \\
\hline Creatinine (mg/dL) & $0.6-1.5$ & 3.67 \\
\hline Glucose $(\mathrm{g} / \mathrm{L})$ & $0.79-1.15$ & 1.31 \\
\hline Calcium (mmol/L) & $2.2-2.55$ & 2.33 \\
\hline Phosphate (mmol/L) & $0.81-1.45$ & 1.52 \\
\hline Creatinine kinase (U/L) & $20-200$ & 321 \\
\hline Lactate dehydrogenase (U/L) & $135-225$ & 182 \\
\hline $\begin{array}{l}\text { Liver enzymes (AST/ALT/GGT/ } \\
\text { ALP) }\end{array}$ & & Normal \\
\hline C-reactive protein (mg/L) & $0-5$ & $<1$ \\
\hline Antinuclear antibodies & & $1 / 640$ \\
\hline Anti-extractable nuclear antigens & & Negative \\
\hline $\mathrm{C} 3(\mathrm{~g} / \mathrm{L})$ & $0.9-1.8$ & 1.09 \\
\hline $\mathrm{C} 4(\mathrm{~g} / \mathrm{L})$ & $0.1-0.4$ & 0.23 \\
\hline \multicolumn{3}{|l|}{24 h Urine } \\
\hline Diuresis & & $2.7 \mathrm{~L}$ \\
\hline Sodium (mmol) & $54-190$ & 172 \\
\hline Potassium (mmol) & $20-80$ & 121 \\
\hline Chloride (mmol) & $46-168$ & 116 \\
\hline Creatinine (mmol) & $3.5-24.6$ & 36.1 \\
\hline Protein $(\mathrm{g})$ & $0.00-0.15$ & 0.45 \\
\hline Protein: creatinine ratio $(\mathrm{g} / \mathrm{g})$ & $0.00-0.15$ & 0.13 \\
\hline Microalbuminuria (g) & $0-20$ & 0.07 \\
\hline Blood (/mL) & $<1000$ & 1200 \\
\hline
\end{tabular}

considered harmless, were known as "legal highs" as their sale was not forbidden. The emergence of undesirable effects similar to those associated with conventional amphetamines [2] led to their being banned in the United States and several European countries, including France [3, 4]. Cathinones come in the form of powder, sometimes tablets, and can be ingested, injected or sniffed, the latter of which is the preferred route of administration due to low oral bioavailability [5]. They are among the most widely used products for chemsex (use of psychoactive products by male homosexuals) due to their stimulating, euphoric effect and increased sexual arousal $[4,6]$.

The adverse effects of cathinones are based on their direct toxicity, sometimes increased by environmental factors. After hepatic metabolism, the metabolites produced are deposited in target organs, including the kidneys, heart and lungs [3]. At the renal level, reported cases mainly show acute functional renal failure, ischemic acute tubular necrosis, acute interstitial nephritis or rhabdomyolysis, which can be severe enough to require dialysis [7, 8]. The drug may also produce hyperthermia (sometimes above $40{ }^{\circ} \mathrm{C}$ ), diaphoresis, and renal vasoconstriction, which may combine with physical exertion in hot, unventilated environments, thus favouring AKI. Underlying chronic renal disease has been identified as a risk factor, which was the case for our patient [3].

3-MMC, a structural isomer of 4-MMC, is thought to have stronger amphetamine-like stimulant properties through inhibition of the dopamine transporter [4].

Most descriptions of cathinone toxicity relate to 4-MMC, while 3-MMC has emerged more recently. In a Swedish study of 50 patients testing positive for 3-MMC, only two patients had severe rhabdomyolysis and only one presented with acute kidney injury. Eight of the patients had hyponatremia. These results need to take into consideration the fact that only 4 of the 50 patients had used 3-MMC alone, and therefore the effects described could have been caused by other drugs they had used [7].

3-MMC is sold under a variety of labels: "research chemical", "bath salts" or "plant food". It is often referred to in the gay community as "drone", "bubble" or even "meow meow" ("miaou miaou" in French) $[5,8]$ in reference to the meowing of cats before their night-time frolics [9].

In our patient, AKI was attributed to a combination of rhabdomyolysis and pre-renal acute kidney injury/AKI on pre-existing CKD combined with 3-MMC use; while the patient did not clinically appear to be dehydrated, he received isotonic saline infusion, which corrected his kidney function.

The anal discharge tested positive for Treponema pallidum, which was treated with BENETHAMINE BENZYLPENICILLIN, 1.2 MIU in one injection. The patient was discharged 3 days after being admitted, upon attainment of his baseline creatinine level.

The present case underlines the importance of considering illicit drug use in all cases of AKI, with particular attention to the new synthetic cathinone 3-MMC, whose emergence could lead to an increase in cases of acute renal failure similar to the one described herein.

Author contributions Conceptualization: SW; data acquisition: SW; drafting the manuscript: SW; critical revision: SW, JPC, SB, GBP; manuscript approval: SW, JPC, SB, GBP.

Funding No funding was received. 


\section{Declarations}

Conflict of interest All the authors declare they have no competing interests.

Ethical statement The authors declare that the patient provided consent for the anonymous report of his medical data in accordance with the guidelines of their hospital's ethics committee.

\section{References}

1. Drogues Info Service. https://www.drogues-info-service.fr/Toutsavoir-sur-les-drogues/Le-dico-des-drogues/Cathinones. Accessed 15 Jan 2021

2. Valente MJ, Guedes de Pinho P, de Lourdes BM et al (2014) Khat and synthetic cathinones: a review. Arch Toxicol 88:15-45. https://doi.org/10.1007/s00204-013-1163-9

3. Carvalho M, Carmo H, Costa VM et al (2012) Toxicity of amphetamines: an update. Arch Toxicol 86:1167-1231. https://doi.org/ 10.1007/s00204-012-0815-5

4. Ferreira B, Dias da Silva D, Carvalho F et al (2019) The novel psychoactive substance 3-methylmethcathinone (3-MMC or metaphedrone): a review. Forensic Sci Int 295:54-63. https://doi. org/10.1016/j.forsciint.2018.11.024

5. Shimshoni JA, Britzi M, Sobol E et al (2015) 3-Methyl-methcathinone: pharmacokinetic profile evaluation in pigs in relation to pharmacodynamics. J Psychopharmacol 29:734-743. https:// doi.org/10.1177/0269881115576687

6. Miotto K, Striebel J, Cho AK, Wang C (2013) Clinical and pharmacological aspects of bath salt use: a review of the literature and case reports. Drug Alcohol Depend 132:1-12. https://doi.org/10. 1016/j.drugalcdep.2013.06.016

7. Bäckberg M, Lindeman E, Beck O, Helander A (2015) Characteristics of analytically confirmed 3-MMC-related intoxications from the Swedish STRIDA project. Clin Toxicol 53:46-53. https://doi. org/10.3109/15563650.2014.981823

8. Luciano RL, Perazella MA (2014) Nephrotoxic effects of designer drugs: synthetic is not better! Nat Rev Nephrol 10:314-324. https://doi.org/10.1038/nrneph.2014.44

9. Brooks R (1958) Cat on a hot tin roof

Publisher's Note Springer Nature remains neutral with regard to jurisdictional claims in published maps and institutional affiliations. 